\title{
Epidemiology of Soft Tissue Sarcoma and Bone Sarcoma in Italy: Analysis of Data from 15 Population-Based Cancer Registries
}

\author{
Sabrina Fabiano, ${ }^{1}$ Paolo Contiero, ${ }^{2}$ Giulio Barigelletti, ${ }^{1}$ Anna D'Agostino, ${ }^{1}$ \\ Andrea Tittarelli, ${ }^{1}$ Lucia Mangone, ${ }^{3}$ Isabella Bisceglia, ${ }^{3}$ Salvatore Bongiorno, ${ }^{4}$ \\ Lucia Elena De Lorenzis, ${ }^{5}$ Guido Mazzoleni, ${ }^{6}$ Marine Castaing, ${ }^{7}$ Teresa Intrieri, ${ }^{8}$ \\ Antonella Puppo, ${ }^{9}$ Giuliano Carrozzi, ${ }^{10}$ Giovanna Maria Sini, ${ }^{11}$ llaria Fontanili, ${ }^{12}$ \\ Lorenza Boschetti, ${ }^{13}$ Rosario Tumino, ${ }^{14}$ Francesca Bella, ${ }^{15}$ AnnaClara Fanetti, ${ }^{16}$ \\ Maurizio Castelli, ${ }^{4}$ Antonio Ardizzone, ${ }^{5}$ Fabio Vittadello, ${ }^{6}$ Salvatore Sciacca, ${ }^{7}$ \\ Gianfranco Manneschi, ${ }^{8}$ Claudia Casella, ${ }^{9}$ Claudia Cirilli, ${ }^{10}$ Filomena Pala, ${ }^{11}$ \\ Maria Michiara, ${ }^{12}$ Simona Migliazza, ${ }^{13}$ Francesca Ferrari, ${ }^{3}$ Eugenia Spata, ${ }^{14}$ \\ Ylenia Dinaro, ${ }^{15}$ Ivan Cometti, ${ }^{16}$ Anna Maghini, ${ }^{1}$ and Giovanna Tagliabue $\mathbb{D}^{1}$ \\ ${ }^{1}$ Cancer Registry Unit, Fondazione IRCCS Istituto Nazionale dei Tumori, 20133 Milan, Italy \\ ${ }^{2}$ Environmental Epidemiology Unit, Fondazione IRCCS Istituto Nazionale dei Tumori, 20133 Milan, Italy \\ ${ }^{3}$ Epidemiology Unit, L'Azienda USL-IRCCS di Reggio Emilia, Reggio Emilia, Italy \\ ${ }^{4}$ Aosta Valley Health Authorities Department of Public Health, Cancer Registry, Aosta, Italy \\ ${ }^{5}$ Cancer Registry Local Health Unit Brindisi-Section of the Puglia Cancer Registry, Brindisi, Italy \\ ${ }^{6}$ Cancer Registry of South Tyrol, South Tyrol, Italy \\ ${ }^{7}$ Integrated Cancer Registry of Catania-Messina-Siracusa-Enna, Department of Hygiene and Public Health, \\ Università di Catania, Catania, Italy \\ ${ }^{8}$ Clinical Epidemiology, Institute for Study and Cancer Prevention, Florence, Italy \\ ${ }^{9}$ Liguria Cancer Registry, IRCCS Ospedale Policlinico San Martino, Genova, Italy \\ ${ }^{10}$ Epidemiology Unit, AUSL of Modena, Modena, Italy \\ ${ }^{11}$ Nuoro Cancer Registry-ATS Sardegna (ASSL Nuoro), Nuoro, Italy \\ ${ }^{12}$ Parma Cancer Registry, Oncology Unit, L'Azienda Ospedaliera-Universitaria di Parma, Parma, Italy \\ ${ }^{13}$ Cancer Registry Epidemiology Monitoring Unit Public Health Agency of Pavia, Pavia, Italy \\ ${ }^{14}$ Cancer Registry and Histopathology Department, Provincial Health Authority (ASP), Ragusa, Italy \\ ${ }^{15}$ Cancer Registry of Siracusa Province, Health Unit of Siracusa Province, Siracusa, Italy \\ ${ }^{16}$ Epidemiology Unit, Health Protection Agency, Sondrio, Italy
}

Correspondence should be addressed to Giovanna Tagliabue; giovanna.tagliabue@istitutotumori.mi.it

Received 10 January 2020; Accepted 3 April 2020; Published 1 September 2020

Academic Editor: Manish Agarwal

Copyright () 2020 Sabrina Fabiano et al. This is an open access article distributed under the Creative Commons Attribution License, which permits unrestricted use, distribution, and reproduction in any medium, provided the original work is properly cited.

Sarcomas are a heterogeneous group of rare cancers of mesenchymal origin. In this study, we provide updated, world agestandardised incidence rate (ASR) and European age-standardised incidence rate for malignant soft tissue sarcoma (ICD-O-3 topographic code C47-C49) and bone sarcoma (C40, C41) in Italy, by area (north, centre, and south) and by cancer registry. We also assess morphology in relation to site and area and assess metastases at diagnosis. We analysed 1,112 cases, with incidence 2009-2012, provided by 15 cancer registries (CRs) affiliated to the Association of Italian Cancer Registries (AIRTUM). Overall, ASR was 1.7/100,000/year for soft tissue sarcoma and 0.7 for bone sarcoma. Central Italy had the highest (2.4) ASR and south Italy had the lowest (1.6) ASR for soft tissue sarcoma. Central Italy had the highest (1.1) ASR and north Italy had the lowest (0.7) ASR for bone sarcoma. By CR, ASRs ranged from 1.1 to 2.6 for soft tissue sarcoma and from 0 to 1.4 for bone sarcoma. The most 
frequent soft tissue sarcomas were sarcoma not otherwise specified (NOS) (29.4\%) and liposarcoma (22.2\%); the most common bone sarcoma was chondrosarcoma (37.6\%). Soft tissue sarcomas occurred most frequently (35.6\%) in lower limb connective tissue; bone sarcomas arose mainly $(68.8 \%)$ in long bones. The frequencies of morphologies arising at different sites varied considerably by Italian area; for example, $20 \%$ of hemangiosarcomas occurred in the head and neck in south Italy with $17 \%$ at this site in the centre and 6\% in the north. For soft tissue sarcoma, the highest ASRs of 2.6 and 2.4 contrast with the lowest ASRs 1.1 and 1.3 , suggesting high-risk hot spots that deserve further investigation. The marked variations in morphology distribution with site and geography suggest geographic variation in risk factors that may also repay further investigation particularly since sarcoma etiology is poorly understood.

\section{Introduction}

Sarcomas are a heterogeneous group of malignant neoplasms of mesenchymal origin. They are one of the major groups of rare cancers in Europe [1] accounting for around $1 \%$ of all cancers diagnosed [2]. The World Health Organization [3] recognises approximately 70 histotypes grouped into two main categories: soft tissue sarcoma and bone sarcoma. In Europe, soft tissue sarcomas are more frequent than bone sarcomas, with world age-standardised incidence rates (ASRs) of 1.5-3.0/100,000/year and 0.5-2.0/100,000/ year, respectively. Both types of sarcoma are moderately more frequent males than females [4].

Soft tissue sarcomas constitute about $84 \%$ of the sarcomas diagnosed in Europe [5]. Accurate diagnosis of these entities is challenging in relation to their rarity and morphologic heterogeneity [6]. Nevertheless, site of origin tends to correlate with certain histotypes. For example, liposarcomas arise mainly in the thigh of young adults, and myxofibrosarcomas often arise in the superficial soft tissue of elderly patients [7]. The most common soft tissue sarcoma histotypes in Europe have been reported as leiomyosarcoma (19\%), liposarcoma (16\%), and sarcoma not otherwise specified (NOS, 14\%) [8].

Bone sarcomas constitute around $14 \%$ of sarcomas diagnosed in Europe [5]. Osteosarcoma, the most frequent bone sarcoma overall (ASR 0.3), generally arises in long bones, but the proportion arising at an axial site increases with age [9]. Chondrosarcoma and Ewing's sarcoma are the most frequent bone sarcomas in adults, with ASRs of 0.2 and 0.3 , respectively [9], followed by chordoma (ASR 0.5/million/year), which arises from persisting notochord [9]. Ewing's sarcoma mainly occurs in children and adolescents but is also seen in adults; it arises in long bones (about $50 \%$ of cases), followed by the pelvis, ribs, and vertebra.

The causes of most sarcomas are unknown. A recent study on 1,162 patients over 15 years with histologically confirmed sarcoma found that $55 \%$ had an excess of pathogenic (and potentially aetiological) germline variants [10]. Several risk factors are well established, including advanced age, previous radiation treatment, previous cancer, and rare genetic conditions [11].

The rarity of sarcomas makes them difficult to study. Single institution reports of incidence, survival, and prevalence are unlikely to be reliable, and pooled data from population-based cancer registries are required to obtain representative data. The aim of the present study is to provide updated estimates of the incidence of malignant soft tissue and bone sarcomas in Italy overall, by area (north, central, and south) and by cancer registry, using data from 15 population-based cancer registries affiliated to the Association of Italian Cancer Registries (AIRTUM) [12]. The presence of metastases at diagnosis and morphology in relation to site-which appears to not have been previously investigated in sarcomas diagnosed in Italy-were also assessed.

\section{Materials and Methods}

Italian cancer registries were asked to provide data on malignant soft tissue and bone sarcoma cases incidence between January 1, 2009, and December 31, 2012, that had at least five years of follow-up. Fifteen population-based cancer registries, all affiliated to AIRTUM, sent in data.

For each case, ICD-O-3 morphology, site (ICD-O-3 topography) [13], age at diagnosis, date of diagnosis, and vital status (with date and cause of death) were also ascertained. Cases were staged at diagnosis according to the 6th or 7 th editions of the TNM $[14,15]$. Sarcomas with organs as primary site were excluded, as were Kaposi's sarcoma and sarcomas of uncertain behaviour. NOS cases were included as this was a population-based study, and completeness was of interest, not simply morphological precision. The populations covered by each cancer registry, stratified by age and sex at January 1 st of each study year, were obtained from the Italian Institute of Statistics (ISTAT) [16].

The cancer registries carried out passive and active follow-up of cases from date of diagnosis to the end of follow-up (December 31, 2017). For this study, north Italy was represented by the cancer registries of Val d'Aosta, Bolzano, Sondrio, Varese, Pavia, Genova, Reggio Emilia, Modena, and Parma. Central Italy was represented by the single registry of Firenze-Prato. South Italy was represented by the registries of Brindisi, Ragusa, Siracusa, CataniaMessina-Enna, and Nuoro. The results are presented overall, by area and by cancer registry. For metastases and morphology in relation to site, data are also presented by age class.

2.1. Statistical Methods. The analyses were descriptive and exploratory in nature. The chi-squared test was used to assess the significance of differences in distribution frequencies between sarcoma categories, using RStudio, version 3.2.5 [17]. Incidence rates (per 100,000 per year, unless otherwise stated) were age-standardised using direct methods and the world standard population 2000-2025 (ASRs) [18]. We also 
present incidence rates age-standardised to the European population [19] to enable comparison with other European studies. Rates were estimated using SEER* Stat statistical software from Surveillance, Epidemiology, and End Results (SEER) [20].

\section{Results}

A total of 1,112 sarcoma cases were diagnosed in 2009-2012 in the areas covered by the 15 registries. There were 859 soft tissue sarcomas and 253 bone sarcomas; $55 \%$ of total cases were in males and $45 \%$ in females. Mean age at diagnosis was 57 years; $44.5 \%$ were of age 65 or more (Table 1 ).

3.1. Incidence. Overall ASRs were 1.7 for soft tissue sarcoma and 0.7 for bone sarcoma (Table 2). Incidence rates agestandardised to European population were 2.5 for soft tissue sarcoma and 0.8 for bone sarcoma. Incidence varied with geographic area (Table 3). For soft tissue sarcoma, ASRs were 2.4 in central Italy, 1.9 in the north, and 1.6 in the south. For bone sarcoma, ASRs were 1.1 in central Italy, 0.7 in the north, and 0.8 in the south.

Incidence also varied with cancer registry (Table 2). For the registries of Valle d'Aosta, Pavia, Brindisi, and Nuoro, ASRs for the two main histotypes varied "in harmony": 1.1, 2.6, 1.4, and 1.4 for soft tissue sarcoma; 0.7, 1.4, 1.0, and 0.4 for bone sarcoma. For other registries, a high incidence of soft tissue sarcoma did not correspond with a high incidence of bone sarcoma: Modena 1.5 for soft tissue sarcoma vs. 0.0 for bone sarcoma; Parma 1.6 for soft tissue sarcoma vs. 0.1 for bone sarcoma; and Ragusa 2.0 for soft tissue sarcoma vs. 0.7 for bone sarcoma. The registry of Pavia had the highest ASR of soft tissue sarcoma (2.6) and bone sarcoma (1.4), followed by Firenze-Prato ( 2.4 for soft tissue sarcoma and 1.1 for bone sarcoma).

3.2. Site and Morphology. As regards site, soft tissue sarcomas arose mainly in the lower extremities (35.6\%) and trunk (33.6\%), while $35.6 \%$ of bone sarcomas arose in the lower limb long bones, $33.2 \%$ arose in the upper limb long bones, and $21.3 \%$ in the trunk (Table 1 ).

Of the 859 soft tissue sarcomas diagnosed, $29.4 \%$ were sarcoma NOS, $22.2 \%$ were liposarcoma, $20.4 \%$ were fibrosarcoma, $16.1 \%$ were leiomyosarcoma, and $4.4 \%$ were rhabdomyosarcoma. Soft tissue sarcoma NOS also included other forms considered relatively aspecific: undifferentiated pleomorphic sarcoma, undifferentiated round cell sarcoma, spindle cell sarcoma, epithelioid sarcoma, and undifferentiated sarcoma NOS.

Among the 253 bone sarcomas diagnosed, 37.6\% were chondrosarcoma-a high proportion related to the elderly population, 29.2\% were osteosarcoma, 13\% were Ewing's sarcoma, and $12.7 \%$ were other bone sarcoma morphologies.

The most frequent soft tissue sarcoma morphologies at each site and by geographic area are shown in Table 4 . In the north, leiomyosarcoma was the most frequent morphology at head and neck (31\%) and abdominal (26\%) sites; liposarcoma was the most frequent morphology in the lower limb (32\%) and trunk (24\%); and fibrosarcoma was the most common in the upper extremity (29\%). In central Italy, sarcoma NOS was the most common (33\%) at abdominal sites; leiomyosarcoma was the most common at the upper extremity (71\%), head and neck (17\%), and trunk (27\%); and fibrosarcoma (29\%) was the most common at the lower extremity and trunk (27\%), while myxosarcoma (17\%) was also common in the head and neck. In the south, leiomyosarcoma (30\%) was the most common in the abdomen; liposarcoma (37\%) was the most common in the lower limbs; fibrosarcoma was the most common in the upper limbs (25\%) and trunk (22\%); and hemangiosarcoma and fibrosarcoma were the most common in the head and neck (20\% each).

The most frequent bone sarcoma morphologies at each site, by geographic area, are shown in Table 5 . In the north, most bone sarcomas were chondrosarcoma (57\% upper limb, $47 \%$ trunk, and $28 \%$ pelvic cases). The second most frequent bone sarcoma in the north was osteosarcoma (42\% of lower extremity and 38\% of head and neck cases). In central Italy, the commonest morphology was chordoma which constituted $50 \%$ of pelvic cases, whereas chondrosarcoma and Ewing's sarcoma accounted for 33\% and $17 \%$, respectively, of pelvic cases, followed by chondrosarcoma which constituted $89 \%$ of lower limb and $100 \%$ of upper limb cases (data not shown). Osteosarcoma constituted $60 \%$ of head and neck cases; $33 \%$ each of trunk cases were Ewing's sarcoma and chondrosarcoma. In the south, the commonest morphology was chondrosarcoma which formed $29 \%$ of pelvic cases, $90 \%$ of upper limb cases, $37 \%$ of facial bone cases, and $45 \%$ trunk bone cases, while $64 \%$ of lower limb cases were osteosarcoma.

3.3. Metastases. A total of $338 / 1,112(30 \%)$ cases had information onstage at diagnosis, 136/338 (40\%) of which had metastatic disease at diagnosis: 109/136 (80\%) from soft tissue sarcoma and 27/136 (20\%) from bone sarcoma. The commonest metastatic sites for soft tissue sarcoma were lung (38\%) and bone (21\%), with liver (15\%) and pleura (6\%) also fairly frequent; $4 \%$ had metastases to the central nervous system (Figure 1). The commonest metastatic sites for bone sarcoma were lung $(58 \%)$, bone $(18 \%)$, and pleura $(6 \%)$ (Figure 2).

Figure 3 shows the most important metastasis sites by age for soft tissue sarcomas. The proportion of soft tissue sarcoma cases with lung metastases increased from $23.1 \%$ in the $0-19$-year age class to $42.6 \%$ in the $50-69$-year age class and declined to $34.4 \%$ in those of $\geq 70$ years. The proportions with bone metastases reduced up to the 50-69-age class to then increase in the oldest group. Metastases to liver increased from $7.7 \%$ in those of $0-19$ years, peaked at $20.4 \%$ in the 50-59-year age class, and declined in the oldest group.

Figure 4 shows the most important metastasis sites by age for bone sarcomas: in the 0-19-year age class metastases involved lungs in $81.8 \%$ of cases and bone in $9.1 \%$. Presentation with lung metastases declined in intermediate ages but increased again (to $57.1 \%$ ) in patients $\geq 70$ years. Pleural metastases became more frequent with increasing age to 
TABLE 1: Characteristics of soft tissue and bone sarcoma cases diagnosed in 2009-2012 and archived in 15 Italian population-based cancer registries affiliated to AIRTUM.

\begin{tabular}{|c|c|c|c|}
\hline & Number & $\%$ & $P$ value* \\
\hline All cases & 1112 & 100.0 & \\
\hline $\begin{array}{l}\text { Mode of diagnosis } \\
\text { From histology of primary } \\
\text { By other means }\end{array}$ & $\begin{array}{c}1028 \\
84\end{array}$ & $\begin{array}{c}92.4 \\
7.6\end{array}$ & \\
\hline $\begin{array}{l}\text { Sex } \\
\quad \text { Male } \\
\text { Female }\end{array}$ & $\begin{array}{l}609 \\
503\end{array}$ & $\begin{array}{l}54.8 \\
45.2\end{array}$ & 0.001 \\
\hline $\begin{array}{l}\text { Age (years) } \\
\quad<20 \\
20-44 \\
45-64 \\
\geq 65 \\
\text { Median age (IQR) }\end{array}$ & $\begin{array}{l}100 \\
204 \\
313 \\
495 \\
62\end{array}$ & $\begin{array}{c}9.0 \\
18.3 \\
28.2 \\
44.5 \\
42-74\end{array}$ & \\
\hline $\begin{array}{l}\text { Morphologies: soft tissue sarcomas }{ }^{\dagger} \\
\text { Sarcoma not otherwise specified (NOS) } \\
\text { Liposarcoma } \\
\text { Fibrosarcoma, peripheral nerve, and others } \\
\text { Leiomyosarcoma } \\
\text { Rhabdomyosarcoma } \\
\text { Hemangiosarcoma } \\
\text { Myxosarcoma } \\
\text { Osteosarcoma } \\
\text { Chondrosarcoma } \\
\text { Desmoplastic tumour } \\
\text { Teratoma } \\
\text { Myoepithelial sarcoma } \\
\text { Other soft tissues }\end{array}$ & $\begin{array}{c}859 \\
253 \\
191 \\
175 \\
138 \\
38 \\
36 \\
16 \\
4 \\
4 \\
1 \\
1 \\
1 \\
1\end{array}$ & $\begin{array}{c}29.4 \\
22.2 \\
20.4 \\
16.1 \\
4.4 \\
4.2 \\
1.9 \\
0.5 \\
0.5 \\
0.1 \\
0.1 \\
0.1 \\
0.1\end{array}$ & \\
\hline $\begin{array}{l}\text { Anatomic location: soft tissue sarcoma } \\
\text { Lower extremity } \\
\text { Upper extremity } \\
\text { Trunk } \\
\text { Others }\end{array}$ & $\begin{array}{c}305 \\
166 \\
289 \\
99\end{array}$ & $\begin{array}{l}35.6 \\
19.3 \\
33.6 \\
11.5\end{array}$ & \\
\hline $\begin{array}{l}\text { Morphologies: bone sarcoma } \\
\text { Chondrosarcoma } \\
\text { Osteosarcoma } \\
\text { Ewing's sarcoma } \\
\text { Other malignant bone tumour } \\
\text { Chordoma } \\
\text { Fibrosarcoma, peripheral nerve, and other fibrous } \\
\text { Hemangiosarcoma } \\
\text { Undifferentiated chordoma }\end{array}$ & $\begin{array}{c}253 \\
95 \\
74 \\
33 \\
32 \\
16 \\
1 \\
1 \\
1\end{array}$ & $\begin{array}{c}37.6 \\
29.2 \\
13.0 \\
12.7 \\
6.3 \\
0.4 \\
0.4 \\
0.4\end{array}$ & \\
\hline $\begin{array}{l}\text { Anatomic location: bone sarcoma } \\
\text { Lower extremity } \\
\text { Upper extremity } \\
\text { Trunk } \\
\text { Others }\end{array}$ & $\begin{array}{l}90 \\
84 \\
54 \\
25\end{array}$ & $\begin{array}{c}35.6 \\
33.2 \\
21.3 \\
9.9\end{array}$ & \\
\hline
\end{tabular}

${ }^{*} P$ values (chi-square test) for differences between subgroups. ${ }^{* *}$ Autopsy, cytology, or histology of metastasis. ${ }^{\dagger}$ Percentages refer to totals in each category, not total number of cases. Bold values indicate totals for soft tissue and bone sarcoma cases, respectively.

peak at $25 \%$ in the $50-69$-year age class and declined in patients $\geq 70$ years.

\section{Discussion}

The 15 AIRTUM cancer registries that contributed data covered an annual mean of 8,183,639 persons over the four- year study period, constituting $13.8 \%$ of the mean annual Italian population of 59,237,407 million during that period.

The data used in this study were checked for quality and completeness, by each cancer registry and by AIRTUM, using automated data checking procedures developed by the International Agency for Research on Cancer [21] and International Association of Cancer Registries, and described in Cancer Incidence in Five Continents Volume XI [22]. The 
TABLE 2: Incidence rates (standardised to the age structure of the world population 2000-2025) of soft tissue and bone sarcoma per 100,000 per year by cancer registry.

\begin{tabular}{|c|c|c|c|c|c|c|c|c|}
\hline \multirow{2}{*}{ Cancer registry } & \multicolumn{4}{|c|}{ Soft tissue sarcoma } & \multicolumn{4}{|c|}{ Bone sarcoma } \\
\hline & Incidence & $95 \% \mathrm{CI}$ & $N$ cases & Population & Incidence & $95 \% \mathrm{CI}$ & $N$ cases & Population \\
\hline Val d'Aosta & 1.1 & $0.5-2.5$ & 9 & 509,781 & 0.7 & $0.2-2.1$ & 5 & 509,781 \\
\hline Brindisi & 1.4 & $0.8-2.4$ & 19 & 800,447 & 1.0 & $0.4-2.1$ & 8 & 800,447 \\
\hline Bolzano & 1.8 & $1.2-2.5$ & 42 & $2,014,656$ & 0.8 & $0.4-1.3$ & 17 & $2,014,656$ \\
\hline Catania-Messina-Enna & 1.5 & $1.2-1.8$ & 157 & $7,644,659$ & 0.8 & $0.6-1.0$ & 54 & $7,644,659$ \\
\hline Genova & 1.4 & $1.0-2.0$ & 60 & $2,650,533$ & 0.6 & $0.3-1.1$ & 17 & $2,650,533$ \\
\hline Modena & 1.5 & $1.1-2.1$ & 65 & $2,726,805$ & 0.0 & $0.0-0.2$ & 0 & $2,726,805$ \\
\hline Nuoro & 1.4 & $0.8-2.4$ & 19 & 869,953 & 0.4 & $0.1-1.1$ & 6 & 869,953 \\
\hline Parma & 1.6 & $1.1-2.2$ & 47 & $1,707,927$ & 0.1 & $0.0-0.4$ & 2 & $1,707,927$ \\
\hline Pavia & 2.6 & $2.0-3.4$ & 91 & $2,171,518$ & 1.4 & $0.9-2.1$ & 32 & $2,171,518$ \\
\hline Reggio Emilia & 1.5 & $1.1-2.0$ & 52 & $2,125,493$ & 0.8 & $0.4-1.4$ & 16 & $2,125,493$ \\
\hline Ragusa & 2.0 & $1.4-3.0$ & 35 & $1,256,260$ & 0.7 & $0.3-1.3$ & 11 & $1,256,260$ \\
\hline Siracusa & 1.6 & $1.1-2.3$ & 40 & $1,610,359$ & 0.9 & $0.5-1.6$ & 12 & $1,610,359$ \\
\hline Sondrio & 1.3 & $0.7-2.4$ & 18 & 728,728 & 0.9 & $0.3-2.0$ & 7 & 728,728 \\
\hline Firenze-Prato & 2.4 & $1.9-3.1$ & 89 & $2,414,666$ & 1.1 & $0.7-1.6$ & 36 & $2,414,666$ \\
\hline Varese & 2.1 & $1.8-2.7$ & 116 & $3,502,772$ & 0.8 & $0.5-1.2$ & 30 & $3,502,772$ \\
\hline Overall & 1.7 & $1.5-1.8$ & 859 & $32,734,557$ & 0.7 & $0.6-0.8$ & 253 & $32,734,557$ \\
\hline
\end{tabular}

Cases diagnosed in 2009-2012 and archived in 15 Italian population-based cancer registries affiliated to AIRTUM.

TABLE 3: Incidence rates (standardised to the age structure of the world population in 2000-2025) of soft tissue and bone sarcoma per 100,000 per year, by Italian region.

\begin{tabular}{|c|c|c|c|c|c|c|c|c|}
\hline \multirow{2}{*}{ Italian region } & \multicolumn{4}{|c|}{ Soft tissue sarcoma } & \multicolumn{4}{|c|}{ Bone sarcoma } \\
\hline & Incidence & $95 \% \mathrm{CI}$ & $N$ cases & Population & Incidence & $95 \% \mathrm{CI}$ & $N$ cases & Population \\
\hline North & 1.9 & $0.5-2.5$ & 500 & $18,138,213$ & 0.7 & $0.5-0.8$ & 126 & $18,138,213$ \\
\hline Central & 2.4 & $1.9-3.1$ & 89 & $2,414,666$ & 1.1 & $0.7-1.6$ & 36 & $2,414,666$ \\
\hline South & 1.6 & $1.2-2.5$ & 270 & $12,181,678$ & 0.8 & $0.6-1.0$ & 91 & $12,181,678$ \\
\hline
\end{tabular}

Cases diagnosed in 2009-2012 and archived in 15 Italian population-based cancer registries affiliated to AIRTUM.

TABLE 4: Most frequent (\% of total) soft tissue sarcomas morphologies at different sites by Italian geographic area. Cases diagnosed in 2009-2012 and archived in 15 Italian population-based cancer registries affiliated to AIRTUM.

\begin{tabular}{lccccc}
\hline Area of Italy & Abdomen & Lower extremity & Upper extremity & Head and neck & Trunk \\
\hline North & $\begin{array}{c}\text { Leiomyosarcoma } \\
(26 \%)\end{array}$ & Liposarcoma (32\%) & Fibrosarcoma (29\%) & Leiomyosarcoma $(31 \%)$ & Liposarcoma (24\%) \\
\hline Central & Sarcoma NOS (33\%) & $\begin{array}{c}\text { Fibrosarcoma } \\
(29 \%)\end{array}$ & $\begin{array}{c}\text { Leiomyosarcoma } \\
(71 \%)\end{array}$ & $\begin{array}{c}\text { Myxosarcoma (17\%) } \\
\text { Leiomyosarcoma (17\%) }\end{array}$ & $\begin{array}{c}\text { Fibrosarcoma (27\%) } \\
\text { Leiomyosarcoma } \\
(27 \%)\end{array}$ \\
\hline South & $\begin{array}{c}\text { Leiomyosarcoma } \\
(30 \%)\end{array}$ & Liposarcoma (37\%) & Fibrosarcoma (25\%) & $\begin{array}{c}\text { Fibrosarcoma (20\%) } \\
\text { Hemangiosarcoma } \\
(20 \%)\end{array}$ & Fibrosarcoma (22\%) \\
\hline
\end{tabular}

TABle 5: Most frequent (\% of total) bone sarcoma morphologies at different sites by Italian geographic area.

\begin{tabular}{|c|c|c|c|c|c|}
\hline \multirow{2}{*}{$\begin{array}{l}\text { Area of } \\
\text { Italy }\end{array}$} & \multicolumn{5}{|c|}{ Site } \\
\hline & Pelvis & Lower extremity & Upper extremity & Head and neck & Trunk \\
\hline North & $\begin{array}{c}\text { Chondrosarcoma } \\
(28 \%)\end{array}$ & Osteosarcoma (42\%) & Chondrosarcoma (57\%) & Osteosarcoma (38\%) & $\begin{array}{c}\text { Chondrosarcoma } \\
(47 \%)\end{array}$ \\
\hline Central & Chordoma (50\%) & $\begin{array}{c}\text { Chondrosarcoma } \\
(89 \%)\end{array}$ & $\begin{array}{c}\text { Chondrosarcoma } \\
(100 \%)\end{array}$ & Osteosarcoma (60\%) & $\begin{array}{c}\text { Chondrosarcoma } \\
\quad(33 \%)\end{array}$ \\
\hline South & $\begin{array}{c}\text { Chondrosarcoma } \\
\qquad(29 \%)\end{array}$ & Osteosarcoma (64\%) & Chondrosarcoma (90\%) & $\begin{array}{c}\text { Osteosarcoma }(37 \%) \\
\text { Chondrosarcoma } \\
(37 \%)\end{array}$ & $\begin{array}{c}\text { Chondrosarcoma } \\
(45 \%)\end{array}$ \\
\hline
\end{tabular}

Cases diagnosed in 2009-2012 and archived in 15 Italian population-based cancer registries affiliated to AIRTUM. 


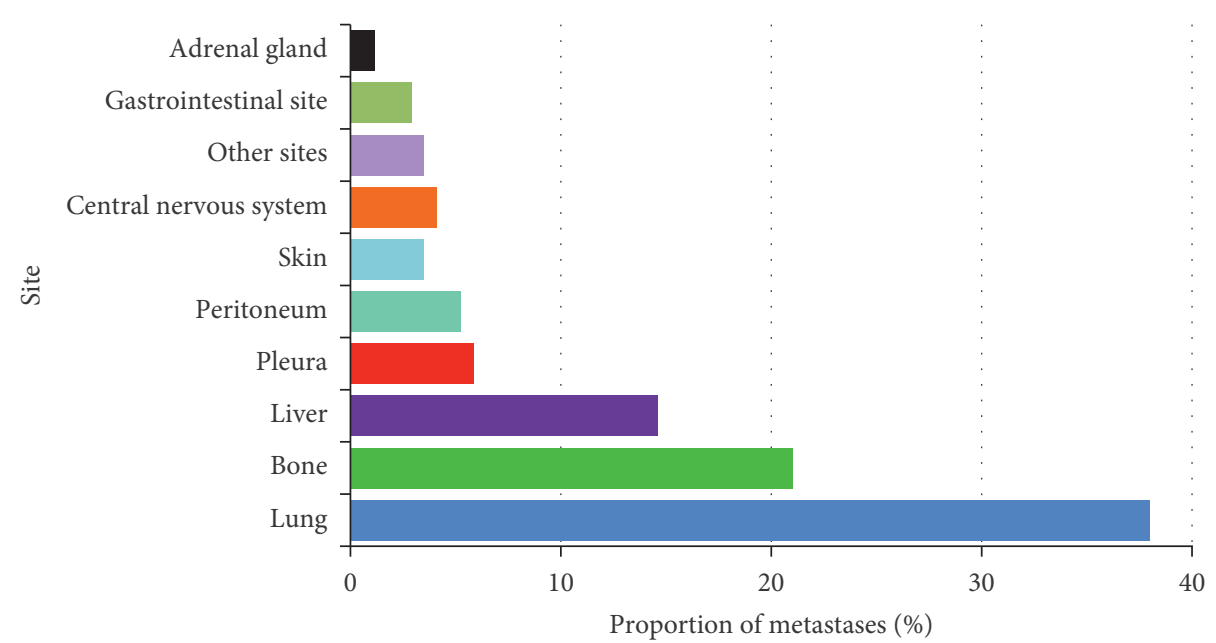

Figure 1: Most frequent metastasis sites for soft tissue sarcomas diagnosed in 2009-2012 and archived in 15 Italian population-based cancer registries.

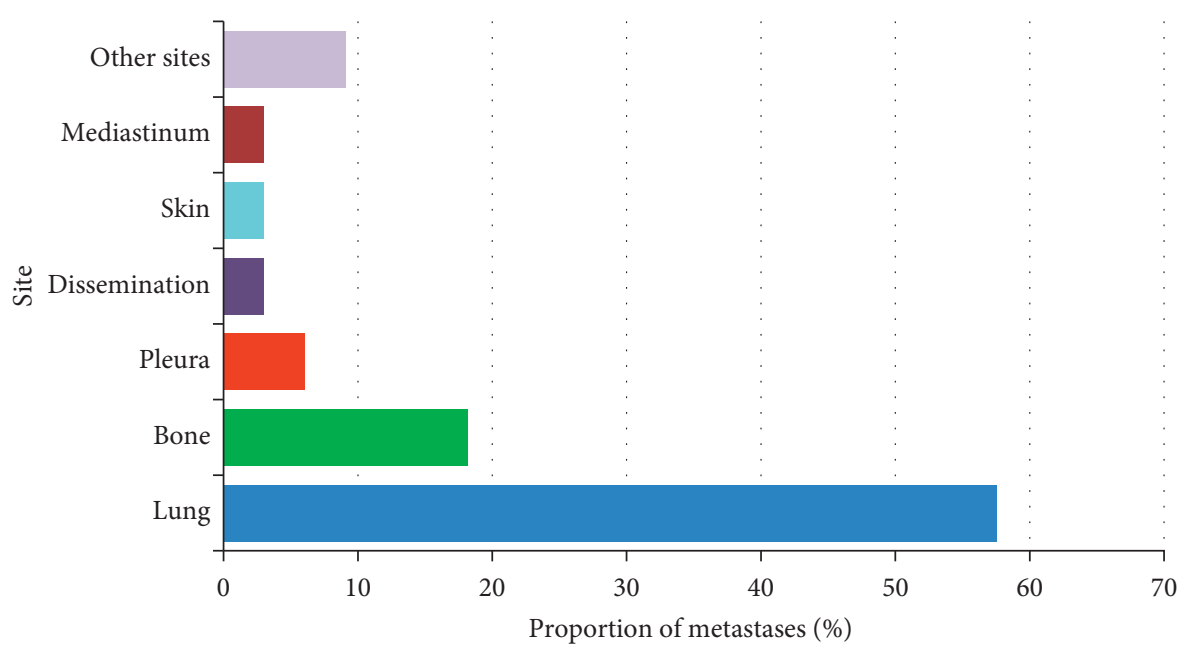

Figure 2: Most frequent metastasis sites for bone sarcomas diagnosed in 2009-2012 and archived in 15 Italian population-based cancer registries.

proportion of microscopically verified cases, a major indicator of data quality, was $95.7 \%$ in our series.

4.1. Incidence. We estimated overall European age-standardised incidence rates of 2.5 for soft tissue sarcoma and 0.8 for bone sarcoma. These figures are similar to populationbased estimates, for Europe as a whole, of 2.3 for soft tissue and 0.7 for bone sarcomas, cases diagnosed in 2000-2007 [23]. Our world age-standardised incidence rates (ASR) estimates of 1.7 for soft tissue and 0.7 for bone sarcoma (Table 2) are lower than and similar to, respectively, ASRs of 3.4 and 0.9 reported for US cases diagnosed in 2009-2012 [24].

It is noteworthy that ASRs varied between cancer registries (Table 2). For soft tissue sarcomas, ASR was highest in Pavia (north Italy) followed by Varese (north), Firenze-Prato (central), and Ragusa (south), with Parma (north) having the lowest ASR. For bone sarcomas, ASR was also highest in Pavia, followed by Firenze-Prato then Brindisi (south), with no cases recorded in Modena (north). ASR variation between cancer registries is unlikely to be due to variation in completeness, since data quality controls were stringent [5]. They are more likely to be due to variation in sarcoma risk factors, particularly, for example, variation in proportion of persons given chemotherapy or radiotherapy for another cancer [25]. The area covered by the Pavia registry is characterized by high mesothelioma incidence [26]. Mesothelioma is known to be caused mainly by exposure to asbestos, leading us to speculate that the high ASRs for sarcomas in Pavia could be related to high levels of workplace or environmental carcinogens [27].

\subsection{Site and Morphology}

4.2.1. Soft Tissue Site. Soft tissue sarcomas develop mainly on the extremities. Hui [25] reported that $28 \%$ of US cases developed on lower extremities and $12 \%$ on upper extremities. The 2005 review of Clark et al. [28], which 


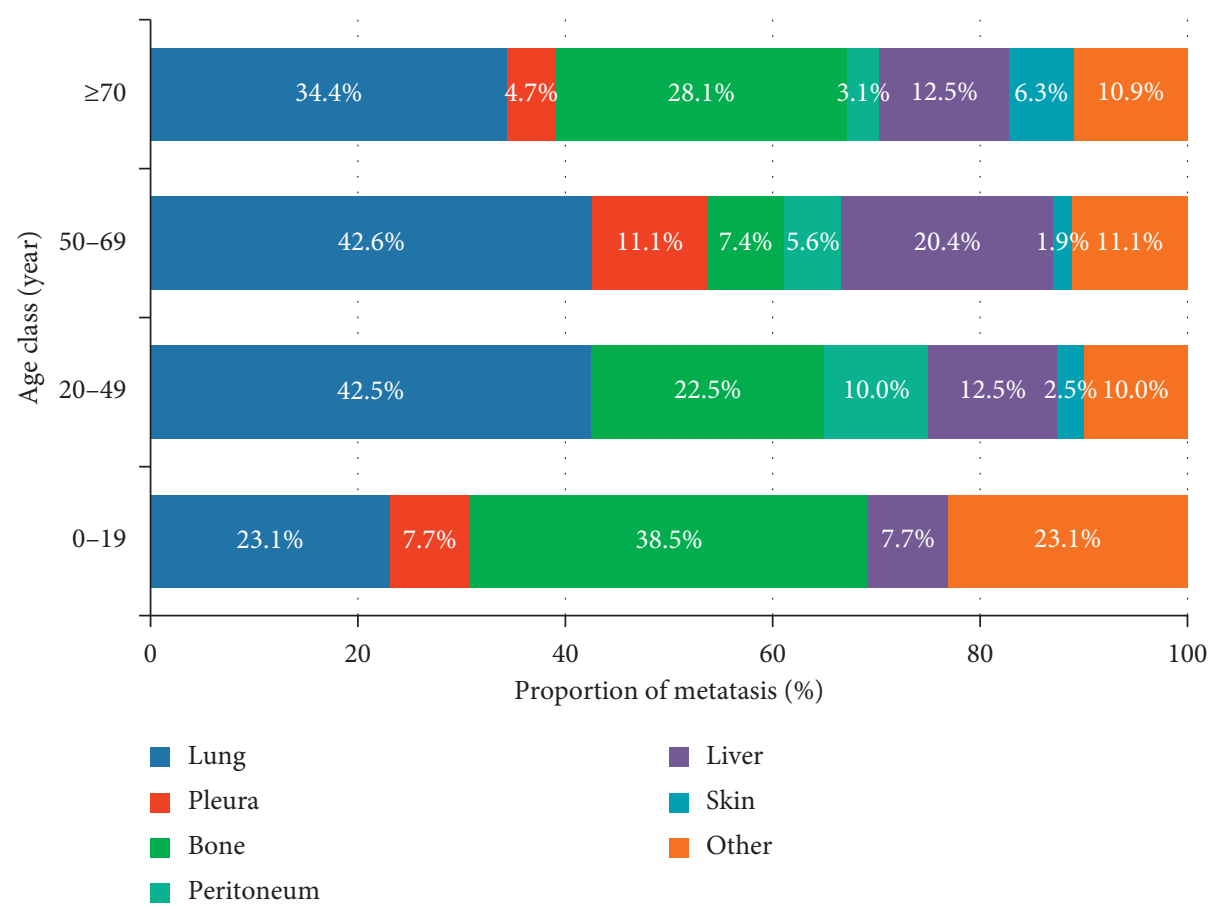

Figure 3: Most important metastasis sites according to age for soft tissue sarcomas diagnosed in 2009-2012 in 15 Italian population-based cancer registries.

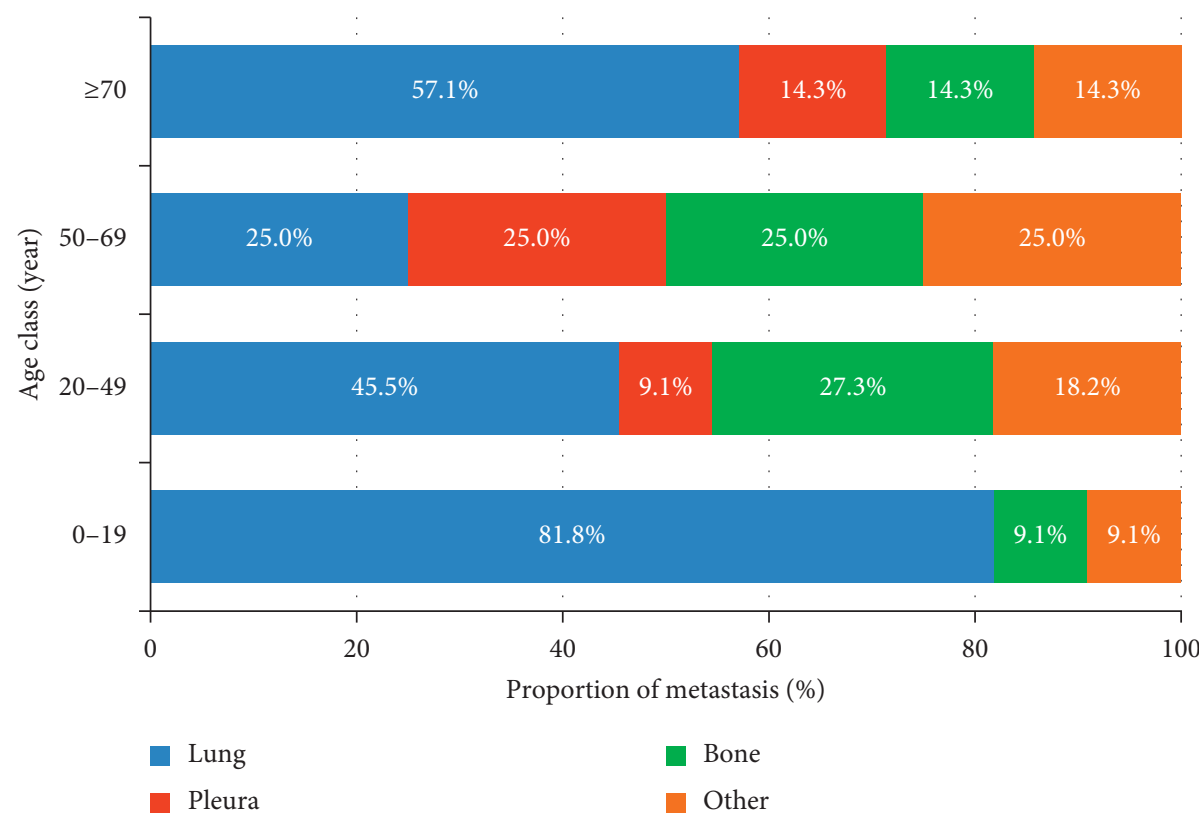

FIGURE 4: Most important metastasis sites according to age for bone sarcomas diagnosed in 2009-2012 in 15 Italian population-based cancer registries.

considered only adult soft tissue cases, reported that $40 \%$ arose on a lower limb or girdle and $20 \%$ arose on an upper limb or girdle. Our findings $(35.6 \%$ on a lower limb and $19.3 \%$ on an upper limb) are in line with the proportions reported by Clark et al. [28]. A 2015 survey of soft tissue sarcomas in France [29] found that in $60 \%$ of cases the disease occurred peripherally ( $49 \%$ on a limb and $11 \%$ head and neck), while the remaining $40 \%$ of cases were truncal
(17\% thoracic, $9 \%$ retroperitoneal, $8 \%$ pelvic, and $6 \%$ abdominal). This difference in site distribution compared to our findings could be due to the fact that the French study included sarcomas of uncertain behaviour as well as those that were frankly malignant.

4.2.2. Bone Site. We found that $35.6 \%$ of bone sarcomas arose in a lower extremity, $33.2 \%$ in an upper extremity 
(predominantly long bone involvement), 21.3\% in trunk, and $9.9 \%$ at other sites. This site distribution is consistent with the morphology distribution (chondrosarcoma $37.6 \%$, osteosarcoma 29.2\%, and Ewing's sarcoma 13\%) in our ageing population.

To our knowledge, data on the subsite distribution of bone sarcomas have not been published previously, so we consider published subsite distributions according to morphology. As regards chondrosarcomas, these arise principally in long bones but can also develop in axial bones (pelvis, ribs, and scapula). Thus, in a population-based series from the Netherlands [30], 50.8\% of chondrosarcoma arose in long bones and $49.2 \%$ in axial bones. In a SEER study, $44.5 \%$ arose in extremities, $31.1 \%$ in axial bones, $14.9 \%$ other bone site, and 9.6\% in soft tissues [31].

As regards osteosarcomas, according to Savage and Mirabello [32], around $80 \%$ of them occur in lower long bones, whereas in a SEER series, $20.8 \%$ occurred on an extremity, $39.3 \%$ in axial bones (pelvis, spine, and ribs), and $19.3 \%$ at another location (mandible, skull, etc.) [33]. It has been reported that axial bone involvement becomes more frequent with advancing age [34]. A Japanese populationbased study reported that $48.9 \%$ of osteosarcomas arose on a lower extremity, $36.9 \%$ on the trunk, and $10.1 \%$ on an upper extremity [35].

As regards Ewing's sarcoma, a SEER study [9] reported the most common primary sites as extremity bones (50\%) followed by pelvis, ribs, and vertebra, although any bone can be affected. Bernstein et al. [36] reported that 26\% of Ewing's sarcomas arose in pelvis, $20 \%$ in femur, $16 \%$ in chest wall, $10 \%$ in tibia, $6 \%$ in humerus, and $2 \%$ in skull. A populationbased study from the Netherlands [30] reported that $56.9 \%$ of Ewing's sarcomas occurred in axial bones and $43.1 \%$ in long bones.

4.2.3. Soft Tissue Morphology. We found that $29.4 \%$ of soft tissue sarcomas were NOS, followed by liposarcoma (22.2\%), fibrosarcoma $(20.4 \%)$, leiomyosarcoma (16.1\%), rhabdomyosarcoma (4.4\%), and hemangiosarcoma (4.2\%). The study of Stiller at al. [4] on EUROCARE 5 cases diagnosed in 2000-2007 from 29 European countries reported that the proportion of NOS sarcomas (likely mainly soft tissue sarcomas) varied from $37 \%$ in Croatia to $4 \%$ in Slovenia, with an overall figure of $13 \%$. Wibmer et al. [37] analysed soft tissue sarcomas diagnosed in 1984-2004 in the Austrian National Cancer Registry, finding that $36 \%$ were NOS. Interestingly, in a RARECARE study [5], 18\% were sarcoma NOS, and $79 \%$ of these soft tissue sarcomas were confirmed as NOS after revision, indicating that even experienced pathologists diagnose sarcoma NOS in a substantial proportion of cases.

We found that morphology distribution by site varied with geographic area in that $20 \%$ of hemangiosarcomas occurred in the head and neck in south Italy (Table 4), compared to $6 \%$ (data not shown) in the north, suggesting geographic variation in the distribution of soft tissue sarcoma risk factors.
4.2.4. Bone Morphology. The most frequent bone sarcoma in our series was chondrosarcoma (37.6\%), which is generally reported as most common bone sarcoma in adults: it is typically low grade and often originated from preexisting benign bone lesions [31]. The 2016 UK guidelines for bone sarcoma management [38] noted chondrosarcoma as the most common bone sarcoma in the ageing UK population. Our population is also ageing $(44.5 \% \geq 65$ years), and our high proportion of chondrosarcomas is consistent with UK findings. The second most frequent bone sarcoma was osteosarcoma (29.2\%). This mainly affects people in the first three decades of life [32]. However, a recent study noted a second incidence peak in persons over 50 years [34], and this is consistent with the high relative proportion of osteosarcomas in our ageing Italian population.

Ewing's sarcoma, the third most common (13.0\%) bone sarcoma in our population, is an aggressive yet highly treatable tumour that mainly affects adolescents and young adults [39]. Genetically Ewing's sarcoma is characterized by balanced chromosomal translocations in which a member of the FET gene family fuses with an ETS transcription factor [39]. As regards geographic variations of site and morphology of bone sarcomas (Table 5), we found that in central Italy proportionately more chordomas arose in the pelvic (sacral) region. A large (400 cases) SEER study of chordomas reported that $32 \%$ of chordomas were cranial, $32.8 \%$ spinal, and $29.2 \%$ sacral [40], suggesting that subsite occurrence within the axial skeleton is in fact more uniform than indicated by our limited data.

In another SEER study [31], 44.5\% of chondrosarcomas arose in upper and lower extremities-similar to the proportion we found in north Italy, but lower than in south Italy. However, comparison is complicated by the fact that $14.9 \%$ of SEER cases had location not specified, while in our study all cases had specified locations.

4.3. Metastasis. Only $30 \%$ of our cases had stage information at diagnosis, $40 \%$ of which were metastatic. In a populationbased study [8] of malignant adult soft tissue sarcomas diagnosed in Germany in 2003-2012, only $18.2 \%$ had stage information at diagnosis, $36 \%$ of which had metastases at diagnosis. Several US SEER-based studies have been published. In one [41] on cases of primary soft-tissue sarcoma occurring on an upper extremity and diagnosed in 1973-1998, only $10.7 \%$ had no stage information, and $4.7 \%$ of the whole population were metastatic at diagnosis. In two more recent SEER studies $[42,43]$ on pediatric soft-tissue sarcomas, all cases had stage information (local, regional, or distant), $15 \%$ of which were metastatic at diagnosis. Clearly, SEER data on pediatric cases are more complete in terms of stage information than European data. According to the follow-up study of Patel et al. [44], disease dissemination in sarcomas occurs mainly by hematogenous as opposed to lymphatic spread $(<5 \%)$; metastases primarily occur in lung, but also bone, liver, regional lymph nodes, peritoneum, distant subcutaneous tissue, and brain, although the preferred metastatic site varies with subtype [45]. We found that 
the main metastatic sites for both soft tissue and bone sarcomas were lung, bone, and pleura; liver was also a frequent metastatic site for soft tissue sarcoma (Figures 3 and 4). Nevertheless, liver was the most common site in adults in the 50-69-year age class, and peritoneum was the most common site in the 20-49-year age class. Our findings are broadly similar to those of Patel et al. [44] and also to those of Shweikeh et al. [46] and Marchiori et al. [47].

\section{Strengths and Limitations}

The main strength of our study is that we used data from AIRTUM chancer registries characterized by high quality (95.7\% of cases microscopically verified) and high completeness. However, the data were not perfect. The large proportions of NOS reflect the difficulties of histopathologic, and increasingly, molecular diagnosis and suggest that sarcoma diagnoses should be routinely reviewed by a pathologist specialised in sarcomas. However, this is not often possible. Another problem is that sarcoma patients are normally treated at specialist centres available outside the cancer registry area and data from centres outside registry areas are not routinely available to cancer registries. AIRTUM is working to ensure that cases treated outside registry areas are not lost to cancer registries.

A second study strength is that we excluded visceral and Kaposi's sarcomas, thereby avoiding the misclassification that is common in sarcomas arising in organs. We emphasize that our cases were population-based, thereby avoiding selection bias, and that we analysed a relatively large number of cases so that our findings are likely to be reliable. Nevertheless, there were low numbers of cases in some soft tissue and bone sarcoma categories, and in these cases, findings should be interpreted cautiously. As a limitation, we note that stage at diagnosis and details of treatment were largely lacking: such information if present would likely have provided additional insights into these rare cancers. In addition, only a few Italian cancer registries use software to automatically generate case data from the data sources (now mostly electronic databases). Automatically generated cases are subjected to checking procedures, and flagged cases undergo manual (operator) checking. Most cancer registries, however, still generate cases manually from clinical records and various electronic databases.

\section{Conclusions}

High sarcoma incidence rates in the cancer registry areas of Pavia and Firenze-Prato suggest that these may be high-risk hot-spots deserving further investigation. Marked variations of morphology distribution with site between Italian areas suggest a more general geographic variation in risk factors that may also repay further investigation, particularly since sarcoma etiology is poorly understood. We are planning an analysis of survival for bone and soft tissue sarcomas archived in the cancer registries that participated in the present study. For this, we will collect information (treatment comorbidities) from clinical records (not available in registry records) to enable us to better interpret survival variations.

\section{Data Availability}

The data on sarcoma cases used in this study were provided by cancer registries affiliated to AIRTUM and cannot be made freely available.

\section{Conflicts of Interest}

The authors declare that there are no conflicts of interest.

\section{Acknowledgments}

The authors thank Don Ward for his help with the English language and for critically reading the manuscript. The authors thank Eli Lilly Italia SpA for the unconditioned support to the study.

\section{References}

[1] G. Gatta, J. M. van der Zwan, P. G. Casali et al., "Rare cancers are not so rare: the rare cancer burden in Europe," European Journal of Cancer, vol. 47, no. 17, pp. 2493-2511, 2011.

[2] D. Forman, F. Bray, D. H. Brewester et al., Cancer Incidence in Five Continents, IARC Scientific Publications No. 164, Lyon, France, 2014.

[3] C. D. M. Fletcher, J. A. Bridge, and P. C. W. Hogendoorn, WHO Classification of Tumours of Soft Tissue and Bone, WHO Classification of Tumours, Lyon, France, 4th edition, 2013.

[4] C. A. Stiller, L. Botta, D. H. Brewster et al., "Survival of adults with cancers of bone or soft tissue in Europe-Report from the EUROCARE-5 study," Cancer Epidemiology, vol. 56, pp. 146-153, 2018.

[5] C. A. Stiller, A. Trama, D. Serraino et al., "Descriptive epidemiology of sarcomas in Europe: report from the RARECARE project," European Journal of Cancer, vol. 49, no. 3, pp. 684-695, 2013.

[6] I. Ray-Coquard, M. C. Montesco, J. M. Coindre et al., "Sarcoma: concordance between initial diagnosis and centralized expert review in a population-based study within three European regions," Annals of Oncology, vol. 23, no. 9, pp. 2442-2449, 2012.

[7] M. Sbaraglia and A. P. Dei Tos, "The pathology of soft tissue sarcomas," Medical Radiology, vol. 124, no. 4, pp. 266-281, 2019.

[8] C. W. Saltus, B. Calingaert, S. Candrilli et al., "Epidemiology of adult soft-tissue sarcomas in Germany," Sarcoma, vol. 2018, Article ID 5671926, 11 pages, 2018.

[9] P. G. Casali, S. Bielack, and N. Abecassis, "Bone sarcomas: ESMO-EURACAN Clinical Practice Guidelines for diagnosis, treatment and follow-up," Annals of Oncology, vol. 29, no. 1, pp. iv79-iv95, 2018.

[10] M. L. Ballinger, D. L. Goode, I. Ray-Coquard et al., "Monogenic and polygenic determinants of sarcoma risk: an international genetic study," The Lancet Oncology, vol. 17, no. 9, pp. 1261-1271, 2016.

[11] N. Penel, J. Grosjean, and Y. M. Robin, "Frequency of certain established risk factors in soft tissue sarcomas in adults: a prospective descriptive study of 658 cases," Sarcoma, vol. 2008, Article ID 459386, 5 pages, 2008. 
[12] Center for Oncological Study and Prevention, Italian Association Cancer Registries, AIRTUM, Center for Oncological Study and Prevention, Firenze, Italy, 2012, https://www. registri-tumori.it/cms/.

[13] A. Fritz, C. Percy, and A. Jack, International Classification of Diseases for Oncology, World Health Organization, Geneva, Switzerland, 2013.

[14] L. H. Sobin and C. Wittekind, TNM Classification of Malignant Tumours, International Union Against Cancer (UICC), Geneva, Switzerland, 6th edition, 2002.

[15] L. H. Sobin, M. K. Gospodarowicz, and C. Wittenkind, TMN Classification of Malignant Tumours, International Union Against Cancer (UICC), Geneva, Switzerland, 7th edition, 2009.

[16] Italian Institute of Statistics, https://www.istat.it.

[17] Research Development Core Team, "R: a language and environment for statistical computing," Research Development Core Team, Vienna, Austria, 2016, http://www.r-project.org.

[18] National Cancer Institute, Surveillance Research Program, National Cancer Institute, Bethesda, MA, USA, 2016, https:// seer.cancer.gov/csr/1975_2016/browse_csr.php?sectionSEL= 35\&pageSEL=sect_a_table.08\#table2.

[19] EUROSTAT, Revision of the European Standard Population, EUROSTAT, Luxembourg, Europe, 2013, https://ec.europa. eu/eurostat/documents/3859598/5926869/KS-RA-13-028-EN. PDF/e713fa79-1add-44e8-b23d-5e8fa09b3f8f.

[20] National Cancer Institute, Surveillance Research Program Seer*;Stat Software version 8.3.4, National Cancer Institute, Bethesda, MA, USA, 2017, https://seer.cancer.gov/seerstat/.

[21] International Association for Cryptologic Research, CI5 X. I.: Cancer Incidence in Five Continents Volume X, International Association for Cryptologic Research, Lyon, France, 2017, http://ci5.iarc.fr/CI5-XI/Pages/Chapter5.aspx.

[22] IARC Technical Report No. 42, Check and Conversion program for Cancer registries, http://www.iacr.com.fr/ images/doc/TechRep42.pdf.

[23] Rare Cancer Network in Europe, http://www.rarecarenet.eu.

[24] National Cancer Institute, Surveillance Research Program, National Cancer Institute, Bethesda, MA, USA, 2016, https:// seer.cancer.gov/statfacts/html/soft.html.

[25] J. Y. C. Hui, "Epidemiology and etiology of sarcomas," Surgical Clinics of North America, vol. 96, no. 5, pp. 901-914, 2016.

[26] C. Mensi, L. Riboldi, S. De Matteis, P. A. Bertazzi, and D. Consonni, "Impact of an asbestos cement factory on mesothelioma incidence: global assessment of effects of occupational, familial, and environmental exposure," Environment International, vol. 74, pp. 191-199, 2015.

[27] Z. Burningham, M. Hashibe, L. Spector, and J. D. Schiffman, "The epidemiology of sarcoma," Clinical Sarcoma Research, vol. 2, no. 1, p. 14, 2012.

[28] M. A. Clark, C. Fisher, I. Judson, and J. M. Thomas, "Softtissue sarcomas in adults," New England Journal of Medicine, vol. 353, no. 7, pp. 701-711, 2005.

[29] C. Honoré, P. Méeus, E. Stoeckle, and S. Bonvalot, "Soft tissue sarcoma in France in 2015: epidemiology, classification and organization of clinical care," Journal of Visceral Surgery, vol. 152, no. 4, pp. 223-230, 2015.

[30] L. M. Goedhart, V. K. Y. Ho, P. D. S. Dijkstra et al., "Bone sarcoma incidence in The Netherlands," Cancer Epidemiology, vol. 60, pp. 31-38, 2019.

[31] A. Y. Giuffrida, J. E. Burgueno, L. G. Koniaris, J. C. Gutierrez, R. Duncan, and S. P. Scully, "Chondrosarcoma in the United States (1973 to 2003): an analysis of 2890 cases from the SEER database," The Journal of Bone and Joint Surgery-American Volume, vol. 91, no. 5, pp. 1063-1072, 2009.

[32] S. A. Savage and L. Mirabello, "Using epidemiology and genomics to understand osteosarcoma etiology," Sarcoma, vol. 2011, Article ID 548151, 13 pages, 2011.

[33] K. R. Duchman, Y. Gao, and B. J. Miller, "Prognostic factors for survival in patients with high-grade osteosarcoma using the Surveillance, Epidemiology, and End Results (SEER) Program database," Cancer Epidemiology, vol. 39, no. 4, pp. 593-599, 2015.

[34] R. Kumar, M. Kumar, K. Malhotra et al., "Primary osteosarcoma in the elderly revisited: current concepts in diagnosis and treatment," Current Oncology Reports, vol. 20, no. 2, p. 13, 2018.

[35] T. Fukushima, K. Ogura, T. Akiyama et al., "Descriptive epidemiology and outcomes of bone sarcomas in adolescent and young adult patients in Japan," BMC Musculoskelet Disord, vol. 19, no. 1, p. 297, 2018.

[36] M. Bernstein, H. Kovar, M. Paulussen et al., "Ewing's sarcoma family of tumors: current management," The Oncologist, vol. 11, no. 5, pp. 503-519, 2006.

[37] C. Wibmer, A. Leithner, N. Zielonke, M. Sperl, and R. Windhager, "Increasing incidence rates of soft tissue sarcomas? A population-based epidemiologic study and literature review," Annals of Oncology, vol. 21, no. 5, pp. 1106-1111, 2010.

[38] C. Gerrand, N. Athanasou, B. Brennan et al., "UK guidelines for the management of bone sarcomas," Clinical Sarcoma Research, vol. 6, p. 7, 2016.

[39] T. G. P. Grünewald, F. Cidre-Aranaz, D. Surdez et al., "Ewing sarcoma," Nature Reviews Disease Primers, vol. 4, no. 1, p. 5, 2018.

[40] M. L. McMaster, A. M. Goldstein, C. M. Bromley, N. Ishibe, and D. M. Parry, "Chordoma: incidence and survival patterns in the United States, 1973-1995," Cancer Causes and Control, vol. 12, no. 1, pp. 1-11, 2001.

[41] A. K. Alderman, H. M. Kim, S. V. Kotsis, and K. C. Chung, "Upper-extremity sarcomas in the United States: analysis of the surveillance, epidemiology, and end results database, 1973-1998," The Journal of Hand Surgery, vol. 28, no. 3, pp. 511-518, 2003.

[42] M. C. Cheung, Y. Zhuge, R. Yang et al., "Incidence and outcomes of extremity soft-tissue sarcomas in children," Journal of Surgical Research, vol. 163, no. 2, pp. 282-289, 2010.

[43] M. Joseph, E. C. Hamilton, A. Hayes-Jordan et al., "The impact of racial/ethnic disparities on survival for children and adolescents with extremity sarcomas: a population-based study," Journal of Pediatric Surgery, vol. 53, no. 17, pp. 30656-30665, 2017.

[44] S. R. Patel, G. K. Zagars, and P. W. T. Pisters, "The follow-up of adult soft-tissue sarcomas," Seminars in Oncology, vol. 30, no. 3, pp. 413-416, 2003.

[45] N. Q. Bui, D. S. Wang, and S. M. Hiniker, "Contemporary management of metastatic soft tissue sarcoma," Current Problems in Cancer, vol. 43, no. 4, pp. 289-299, 2019.

[46] F. Shweikeh, L. Bukavina, and K. Saeed, "Brain metastasis in bone and soft tissue cancers: a review of incidence, interventions, and outcomes," Sarcoma, vol. 2014, Article ID 475175, 19 pages, 2014.

[47] E. Marchiori, M. Menna Barreto, and G. Zanetti, "Pleural metastasis of osteosarcoma," The Annals of Thoracic Surgery, vol. 105, no. 2, pp. e87-e88, 2018. 